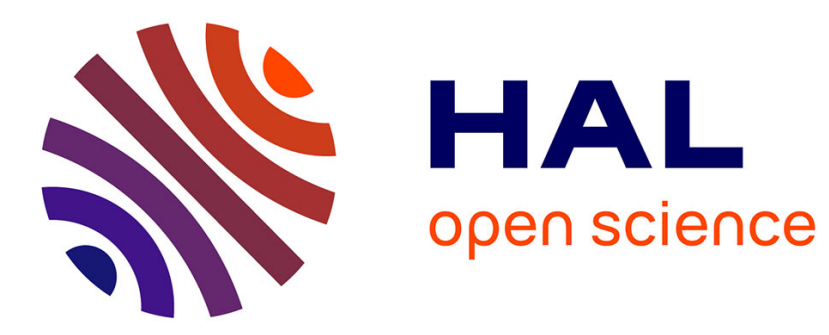

\title{
Development of a simple, low-cost and rapid thin-layer chromatography method for the determination of individual volatile fatty acids
}

F. Robert-Peillard, Elodie Mattio, Aïnhoa Komino, Jean-Luc Boudenne, Bruno Coulomb

\section{To cite this version:}

F. Robert-Peillard, Elodie Mattio, Aïnhoa Komino, Jean-Luc Boudenne, Bruno Coulomb. Development of a simple, low-cost and rapid thin-layer chromatography method for the determination of individual volatile fatty acids. Analytical Methods, 2019, 10.1039/c9ay00158a . hal-02090448

\section{HAL Id: hal-02090448 \\ https://hal.science/hal-02090448}

Submitted on 4 Apr 2019

HAL is a multi-disciplinary open access archive for the deposit and dissemination of scientific research documents, whether they are published or not. The documents may come from teaching and research institutions in France or abroad, or from public or private research centers.
L'archive ouverte pluridisciplinaire HAL, est destinée au dépôt et à la diffusion de documents scientifiques de niveau recherche, publiés ou non, émanant des établissements d'enseignement et de recherche français ou étrangers, des laboratoires publics ou privés. 
Development of a simple, low-cost and rapid thin-layer chromatography method for the determination of individual volatile fatty acids

Fabien Robert-Peillard `, Elodie Mattio, Aïnhoa Komino, Jean-Luc Boudenne, Bruno Coulomb Aix Marseille Univ, CNRS, LCE, Marseille, France.

*Corresponding author: fabien.robert-peillard@univ-amu.fr

\section{Abstract}

In this paper, a new thin-layer chromatography (TLC) method for the determination of individual volatile fatty acids (VFA) is presented. The experimental procedure is based on the derivatization of VFA with activating agents and a naphthalene-based amine to form an amide derivative, followed by fast TLC separation of these VFA derivatives and visualization with phosphomolybdic acid at room temperature. Quantification is then performed by densitometric measurements using a free software after TLC pictures in a home-made black box for homogeneous and reproducible lighting of the plates. Optimization of the experimental conditions enables fast determination (20 minutes for 3 samples) of VFA with detection limits (1.5-2.5 mg. $\left.\mathrm{L}^{-1}\right)$ and relative standard deviations (4.6-6.7\%) satisfactory enough for our analytical purpose using low-cost instruments with easy to find materials and software. The protocol was then applied to real samples (aqueous extracts of sewage sludge composts) and results were compared with gas chromatography analysis with good agreement between the two methods.

Keywords: Volatile fatty acids, thin-layer chromatography, low-cost, environmental analysis.

\section{Introduction}

Anaerobic digestion of biomass leading to biogas production has raised considerable attention over the past years, with applications such as wastewater [1], sewage sludge [2], organic wastes [3] or landfill leachates [4]. The challenge for anaerobic digestion processes is to maintain a stable fermentation process and consistent biogas production, and the monitoring of several parameters such as $\mathrm{pH}$, alkalinity or biogas production rate has been proposed to this end [5]. However, it has been widely acknowledged that volatile fatty acids (VFA) concentrations (in particular acetic, propionic, isobutyric, butyric, isovaleric and valeric acid) provide the most meaningful measure for assessing the effectiveness of the digestion process [6]. Indeed, VFA are produced and consumed during the main stages of anaerobic 
digestion processes (hydrolysis, acidogenesis, acetogenesis, and methanation), and this parameter therefore reflects best the metabolic state of the biochemical process.

VFA measurement can provide two types of information: total VFA (sum of all VFA expressed as $\mathrm{mg} / \mathrm{L}$ as acetic acid) or speciation of individual VFA. Total VFA is often used as control parameter as relatively simple analytical methods such as titration [7], near-infrared spectroscopy [8] or spectrophotometry [9] are available for research or operational laboratories. Despite this simplicity, total VFA measurements can be insufficient for precise optimization of anaerobic digesters, as understanding of the composition of VFA during all stages of the digestion process is also a key point. Indeed, VFA speciation results enable operators to monitor the current state of the anaerobic digesters and adjust the operational strategies to improve performance. Accumulation of propionate is a common indicator of stress in an anaerobic digester [10-12], and traditional non-differentiating methods like titration cannot give early alert for this potential stress that may lead to detrimental bacterial community change and process failure. Moreover, analytical techniques which give individual VFA composition also show strong interests for bioplastic production field which rely on VFA as carbon source, for example for polyhydroxyalkanoates production [13]. It can thus be concluded that there is an urgent need for simple analytical tools for speciation of VFA in operational laboratories monitoring anaerobic digesters performances.

Traditionally, speciation of VFA is performed by gas chromatography, liquid chromatography or capillary electrophoresis [14-17]. These methods based on separation techniques can all provide reliable results, but their relative complexity requiring skilled personnel and high purchase and operational costs (separation columns, eluents, gases...) strongly limit their use for operational laboratories which prefer simple and low-cost analytical tools for routine analysis. Among separation techniques, Thin-Layer Chromatography (TLC) is the oldest one and certainly the simplest and least expensive tool in analytical chemistry. Many studies have already proposed TLC as an alternative to more modern and complex chromatographic system for quality control and fast quantitative or semi-quantitative determination [18-21]. Due to its simplicity, sample clean-up can be minimized, and cross-contaminations or columns clogging are avoided, which are significant advantages for complex samples such as sewage sludge or wastewater.

Our research group has developed an original procedure for the determination of total VFA by batch procedure or microplate assays $[22,23]$. The analytical methodology is based on a specific derivatization of VFA via a two-step mechanism: (i) activation step with two activating agents at acidic $\mathrm{pH}$; (ii) amidation step with a fluorescent amine at basic $\mathrm{pH}$. This methodology was also applied for the development of a multi-syringe chromatography system for the determination of individual VFA [24]. This system was based on the separation of VFA derivatives on a $\mathrm{C}_{18}$ monolithic column and quantification by $\mathrm{UV}$ or 
fluorescence detection, and it could serve as a relatively simple and low-cost on-line analyzer compared to complex on-line chromatographic systems.

In the present paper, a very simple and rapid TLC method for the determination of individual volatile fatty acids is presented. This method is intended as an analytical tool for operational laboratories monitoring anaerobic digesters performances or other environmental samples who cannot afford HPLC or GC but require routine, rapid and low-cost measurement of individual VFA (without sending samples to external laboratories). The procedure is based on previously-mentioned derivatization of VFA combined with fast TLC separation of VFA derivatives and visualization with phosphomolybdic acid at room temperature. Development and application of this procedure for quantitative determination of VFA are presented herein.

\section{Experimental}

\subsection{Reagents, solutions and materials}

All chemicals and solvents were of analytical or HPLC reagent grade and used without further purification. Cyclohexane and ethyl acetate were purchased from Sigma-Aldrich. "EDC solution" was a solution of the activating reagent $\mathrm{N}$ '-(3-dimethylaminopropyl)-Nethylcarbodiimide (EDC) (Sigma-Aldrich) prepared at $100 \mathrm{~g}^{-\mathrm{L}^{-1}}$ in absolute ethanol (EtOH) (Sigma-Aldrich). "HOAT+EDAN solution" was a solution of the secondary activating reagent 7-aza-1-hydroxybenzotriazole (HOAT) (Genscript Corporation, Piscataway, USA) at 6 g.L.1 and the derivatizing reagent N-(1-naphthyl)ethylenediamine (EDAN) (Sigma-Aldrich) at $2 \mathrm{~g} . \mathrm{L}^{-}$ ', prepared as a mixed solution in ultrapure water (Millipore, resistivity $>18 \mathrm{M} \Omega \mathrm{cm}$ ) with final $\mathrm{pH}$ set at 3.6. "KH $\mathrm{KHO}_{4}$ solution" was made of potassium dihydrogen phosphate $\left(\mathrm{KH}_{2} \mathrm{PO}_{4}\right)$ prepared at $250 \mathrm{mM}$ in $\mathrm{NaOH} 0.35 \mathrm{M}$. "PMA solution" was prepared by dissolving phosphomolybdic acid hydrate (PMA) (Sigma-Aldrich) at $3 \% \mathrm{w} / \mathrm{v}$ in water. Stock solutions of carboxylic acid standards (5000 mg L-1 for acetic acid, $1500 \mathrm{mg} \mathrm{L}-1$ for other VFA) (Acros Organics, Geel, Belgium) were prepared in ultrapure water.

Thin layer chromatography aluminum plates $(20 \times 20 \mathrm{~cm}, 0.25 \mathrm{~mm}$ layer thickness) precoated with silica gel 60F-254 were obtained from Merck (Darmstadt, Germany) and cut at adequate dimensions for intended use $(6 \times 6 \mathrm{~cm})$. Spots were applied on the plates at $1.3 \mathrm{~cm}$ height from lower edge of the plate and were separated by a minimum distance of $0.8 \mathrm{~cm}(6$ spots possible on a single plate).

\subsection{Samples}

Real samples used for validation were aqueous extracts of composts (extraction protocol described in Supplementary material) made by mixing anaerobically digested sewage sludge (from Marseille's sewage sludge treatment plant) with green wastes (1/3-2/3, v/v). Ages of 
the composts were between 1 month (AN1) and 6 months (AN 5). All samples were filtered through $0.45 \mu \mathrm{m}$ membrane filters (PES membrane, Millipore, France).

\subsection{Analytical protocol for VFA determination}

In a $2 \mathrm{~mL}$ glass vial were added $300 \mu \mathrm{L}$ of "HOAT+EDAN solution", $250 \mu \mathrm{L}$ of sample and 40 $\mu \mathrm{L}$ of "EDC solution". The vial was stirred and left to react for 5 minutes. $75 \mu \mathrm{L}$ of " $\mathrm{KH}_{2} \mathrm{PO}_{4}$ solution" were then added and the vial was again left to react for 1 minute after proper stirring. $3 \mu \mathrm{L}$ of the reaction mixture was then manually spotted on the TLC plate using $3 \mu \mathrm{L}$ micropipettes (Brand) and the spots were dried with a simple hair-dryer set at minimum heating power until evaporation of water. The plates were developed vertically for $5 \mathrm{~min}$ (solvent front at about $0.5 \mathrm{~cm}$ from upper edge of the plate) at room temperature $\left(22^{\circ} \mathrm{C}\right)$ in a $100 \mathrm{~mL}$ polypropylene disposable tank equipped with a plastic top (Tecan) in order to minimize organic solvent volumes used for development $(1 \mathrm{~mL}$ is enough in these tanks; classical TLC development chambers with higher volumes can be used). Mobile phase was a mixture of ethyl acetate and cyclohexane (60:40, v/v). After development, the plates were dried with the hair-dryer for $1 \mathrm{~min}$. Spots were visualized by dipping the plate in the PMA solution for $10 \mathrm{~s}$ (in a $100 \mathrm{~mL}$ polypropylene disposable trough) and drying the plate on absorbent paper. A picture of the plate was taken immediately with a smartphone in a homemade black box protected from ambient light with a hole for smartphone camera. Homogeneous and reproducible lighting of the plates in the box was provided by a LED strip (12 V DC, $400 \mathrm{Lm}, 24 \mathrm{LED} / \mathrm{m}$ ) cut at the dimensions of the box and stuck on the upper part of the box. Drawing of the box on CAD software is presented in supplementary material section. Quantitative determination of VFA was performed on a personal computer using the open-source ImageJ software (National Institutes of Health) and its densitometric analysis tool. Pictures were analyzed without modification using a constant rectangular selection size between calibration plates and sample plates. Gel analysis tools were used to trace densitometric histograms of each VFA lane and peaks areas were calculated using the wand tool (results can be saved as an excel file for further analysis).

\subsection{Retention factors and resolution between VFA spots}

The retention factor $R_{f}$ was determined directly on the TLC picture and was defined as the ratio of the distance traveled by the center of a spot to the distance traveled by the solvent front.

The resolutions between two neighboring spots $A$ and $B\left(R_{S(A / B)}\right)$ were calculated on the densitometric histograms given by the gel analysis tools of Image J. Resolutions were calculated as the ratio between the difference of distance of peaks maximum and the average of peak widths at base. 


\subsection{Gas chromatography analyses}

VFA were determined under classical GC conditions using a Varian CP-3800 gas chromatograph (GC) with a free fatty acid phase (FFAP) 25 m fused silica capillary column of $0.1 \mu \mathrm{m}$ film thickness and an i.d. of $0.25 \mathrm{~mm}$ (Varian CP-WAX 58-CB). The GC oven temperature was programmed to be incremented from 115 to $140^{\circ} \mathrm{C}$ within $5 \mathrm{~min}$, and a final temperature of $140{ }^{\circ} \mathrm{C}$ was then held for $1.25 \mathrm{~min}$. The injector and detector temperature were set at $290^{\circ} \mathrm{C}$ and $300^{\circ} \mathrm{C}$, respectively. Helium was used as carrier gas at a pressure of 1.4 bar. A flame ionisation detector (FID) was used and quantification was performed using internal standard method. Limits of detection between $3 \mathrm{mg} \mathrm{L}^{-1}$ (valeric acid) and $10 \mathrm{mg} \mathrm{L}^{-1}$ (acetic acid) were obtained. All sample analyses were performed in duplicate

\section{Results}

Experimental conditions for the derivatization of VFA were similar as those used in a previous study with the Multi-Syringe Chromatography set-up [24]. The only differences are the concentrations of the reagents (100 g.L-1 for EDC and 2 g.L-1 for EDAN) which have been increased in order to gain sensitivity. The main experimental optimizations for the work described here are related to the TLC application which gives full interest to the analytical protocol and its intended use.

\subsection{Visualization solution of the spots}

Many visualization methods (or stains) can be used for TLC, which can be compound specific (Dragendorff reagent, ninhydrin...) or universal (iodine, vanillin, phosphomolybdic acid...), with varying preparation complexity and hazardous nature of reagents (strong acids or toxic reagents). As the method is intended for operational laboratories, visualization method with adequate sensitivity, simple preparation procedure and relatively harmless reagents is preferable. Phosphomolybdic acid (PMA) was thus selected based on these criteria, as it is a well-known, sensitive and cheap reagent with low toxicity and wich doesn't require strong acids for the preparation of the visualization solution. Usually, PMA is used as a solution in EtOH and analytes are visualized as dark green to black spots after heating with a heat gun or a hot plate. In our first experiments, we noticed that PMA solution in water was also suitable for visualization of our VFA derivatives spots and that no heating was required after dipping plates in aqueous PMA, which prevents risks associated with the use of heating gun and flammable organic solvents. Moreover, naked-eye comparison of spots visualized with PMA in EtOH or PMA in water (Figure 1) proved that aqueous PMA was the best choice for our application as the spots were much more visible and darker. 


\subsection{Mobile phase selection and retention factors}

Many organic solvents are used for TLC development with silica gel plates (the most common and least expensive stationary phase), including highly toxic solvents such as chloroform, benzene, toluene or hexane. Nowadays, a classical mixture of organic solvents used for TLC development is cyclohexane/ethyl acetate, due its good efficiency to separate compounds with various polarities and functional groups, and also to its moderate toxicity compared to previously-mentioned solvents. Mobile phases with a mixture of these two solvents in various proportions were optimized on a VFA solution containing acetic, propionic, butyric and valeric acids at $100 \mathrm{mg}^{-1}$ (Figure 2). Resolutions between each VFA were calculated accurately on densitometric histograms plotted from the TLC pictures and are given in Table 1. As can be seen, mobile phase made with ethyl acetate/cyclohexane with volume composition of 60:40 provided the best results with optimal separation between the closest spots (propionic, butyric and valeric acid). Addition of other classical TLC mobile phase components like formic acid, diethylamine, ethanol or ammonium hydroxide didn't improve results. Retention factors with this mobile phase $(60: 40, \mathrm{v} / \mathrm{v})$ were also calculated for comparison with real samples: acetic acid: 0.24; propionic acid: 0.43 ; butyric (+isobutyric) acid: 0.55 ; valeric (+isovaleric) acid: 0.64 .

\subsection{Interferences}

The optimized protocol with TLC separation was applied to a wide range of organic compounds likely to be detected under the reaction conditions such as other carboxylic acids (formic, lactic, tartaric, succinic, oxalic, malic, maleic, citric, pyruvic, benzoic acid), carbohydrate (glucose) or amino acids (glycine, alanine, cysteine). Spots of potential derivatives or native compounds visualized at the end of the protocol were compared to VFA spots (comparison of $R_{f}$ and intensity). Most of potential interfering compounds didn't lead to any spots after derivatization and TLC visualization. Only formic, lactic and succinic acid were visible on the TLC pictures (Figure 3), with concentrations 2.5 times higher than VFA in order to be able to visualize corresponding spots. Succinic acid gives the highest response but $R_{f}$ of its derivatives is much lower than VFA. Formic and lactic acid derivatives have similar $R_{f}$ to acetic acid, but intensity of the response is much lower. If we compare these carboxylic acids with acetic acids at the same concentration, intensity response obtained with densitometric histograms is $<4 \%$ of that of acetic acid. Other carboxylic acids tested (tartaric, oxalic, malic, maleic, citric, pyruvic, benzoic acid) led to no appreciable response even at 500 mg. $\mathrm{L}^{-1}$. Considering the expected prevalence of VFA in real samples analyzed by this method, it is reasonable to conclude that VFA measurements with this TLC protocol should be free of interference from other compounds. 


\subsection{Analytical features}

Analytical features of the method are summarized in Table 2, with TLC picture and associated densitometric histograms of a VFA calibration range between 10 and $125 \mathrm{mg} \cdot \mathrm{L}^{-1}$ represented on Figure 4 (left part). Polynomial regression equations were obtained, probably due to the visualization and detection method. Calibration ranges can be easily modified (increase of the lowest and highest bound of the calibration range) by reducing sample volume, depending on real samples analyzed. For example, reducing sample volume to 25 $\mu \mathrm{L}$ enables an extension of the calibration ranges above $1 \mathrm{~g} \cdot \mathrm{L}^{-1}$, which will be more adapted to VFA concentrations in sewage sludge samples. Detection limits and quantification limits have been evaluated based on repetitions $(n=7)$ of a sample spiked at $7 \mathrm{mg} \cdot \mathrm{L}^{-1}$ of each VFA, following U.S. EPA guidelines [25]. Detection limits and quantification limits were between 1.5-2.5 mg. $\mathrm{L}^{-1}$ and 4.7-7.9 mg. $\mathrm{L}^{-1}$, respectively. These limits were clearly low enough for our analytical purposes and were in the same range as those obtained by the GC-FID method used in our laboratory. Finally, relative standard deviation (RSD) between 4.6 and $6.7 \%$ were obtained after application of the whole protocol on a $50 \mathrm{mg} \cdot \mathrm{L}^{-1}$ standard $(n=7$, with one TLC plate for each repetition). Precision with our method is therefore lower than that usually obtained with TLC scanner and dedicated data analysis software [18, 26], but is satisfactory enough for our analytical purpose using low-cost instruments with easy to find materials and software.

\subsection{Analytical costs}

The aim of the method described in this article is to provide a low-cost analytical tool to operational laboratories for which GC or HPLC is too expensive, both as investment and routine usage. Investment for specific equipment for our method is very low, as only standard vials, glassware and pipettes are necessary. Operational costs are summarized in Table 3 and each sample analysis costs globally only $0.12 €$, which makes this method indeed very affordable

\subsection{Comparison with other TLC method for VFA determination}

Direct TLC detection of VFA (without derivatization) is of course possible but detection limits are obviously too high (g. $\mathrm{L}^{-1}$ range [27]) for our analytical application. Derivatization prior to TLC separation and detection is therefore mandatory to reach $\mathrm{mg} \cdot \mathrm{L}^{-1}$ detection range. In spite of the clear advantages that TLC techniques could provide for VFA determination 254 (simplicity, no sample clean-up and cross contaminations, cost), only one method has been published in the literature for derivatization of VFA and ppm detection. This derivatization method is very tedious and time-consuming, as it requires neutralization of the sample, 
evaporation to dryness, boiling for $1 \mathrm{~h}$ with derivatization reagent, extraction with chloroform and evaporation to dryness of organic extracts [28]. In comparison, our method only requires reaction at room temperature for 6 min with non-toxic reagents and direct spotting of the mixture without evaporation (analytical step which has to be avoided for simplicity reasons for routine analysis as described in this study).

Therefore, no TLC method suitable for easy and practically applicable determination of individual VFA were described so far in the literature. Regarding our method, staff effort is moderate, as it takes only about 20 minutes to perform the whole analytical protocol (from derivatization to TLC final picture) for 3 samples (or 6 if no duplicates is performed), and technicity required for the routine application of the protocol is quite low, as no complex instruments are needed. This method is therefore well suited in laboratories where the global operational needs and costs for analytical tools are decisive for the routine and precise monitoring of their process.

\subsection{Validation on real samples}

A comparative study between our TLC method and GC-FID analysis has been conducted on real samples. This validation study was performed on a set of aqueous extracts of composts (made from anaerobically digested sewage sludge and green wastes) which were analyzed in our lab for their VFA content in the frame of a research project dealing with compost monitoring and early warning parameters (VFA was one of the studied parameters, as considerable variation of VFA has already been demonstrated in composting platform [29]). TLC picture and densitometric histograms used for quantification are shown on Figure 4 (right part) for comparison with the calibration range used (scales for the left and right histograms are different and peak heights can't be compared visually). As expected, it can be observed visually that acetic acid is the prevalent VFA in the compost extracts with a noticeable evolution of VFA during the composting process (increase from AN1 to AN3 during bio-oxidation phase and decrease for older composts during maturation phase). Quantitative results for individual C2-C5 VFA concentrations measured by our method or by GC-FID are detailed in Table 4. Results between both methods are in good agreement, with only slight underestimation by our TLC method. Standard deviations are also higher for the TLC method, but results are globally very satisfactory if we consider the simplicity of the material used for visualization and quantification. Note that semi-quantitative measurements could be possible by simple naked-eye comparison with the standard TLC plates for operational laboratories which just need early warning of a sudden change in VFA concentration or composition.

\section{Conclusions}


We have demonstrated that individual VFA determination and quantification using one of the simplest separation technique (thin-layer chromatography) is indeed possible for environmental analysis. Derivatization of VFA using a simple and rapid procedure at room temperature leads to the formation of derivatives which can be easily separated on silica gel TLC plates and detected without heating by simple dipping in a visualization solution. Use of a home-made black box enables reproducible smartphone pictures for subsequent quantification with a free software. As investment and operational costs are very low, this analytical method is perfectly suited for operational laboratories which can't afford on-site HPLC or GC analysis but require routine, rapid and low-cost measurement of individual VFA. The proposed method could therefore supplement classical titrimetric methods which only gives access to total VFA with no details on VFA composition, although this parameter is more and more recognized for its meaningful significance for the monitoring of anaerobic digestion processes.

\section{Acknowledgment}

This work was financially supported by the French Environment and Energy Management Agency (ADEME) through the programme "ODIAMAC" [Convention n¹506C0034].

\section{Literature cited}

[1] N. Narkis, S. Henefeld-Fourrier, M. Rebhun, Volatile organic acids in raw wastewater and in physicochemical treatment. Water Res., 14 (1980), 1215-1223.

[2] B. Ruffino, G.Campo, G.Genon, E. Lorenzi, D.Novarino, G.Scibilia, M. Zanetti, Improvement of anaerobic digestion of sewage sludge in a wastewater treatment plant by means of mechanical and thermal pre-treatments: Performance, energy and economical assessment. Bioresource Technol., 175 (2015), 298-308.

[3] B. Chatterjee, D. Mazumder, Anaerobic digestion for the stabilization of the organic fraction of municipal solid waste: A review. Environ. Rev. 24 (2016), 426-459.

[4] M. Kawai, M. Kishi, M.R. Hamersley, N. Nagao, J. Hermana, T. Toda, Biodegradability and methane productivity during anaerobic co-digestion of refractory leachate. Int. Biodeter. Biodegrad., 72 (2012), 46-51.

[5] K. Boe, D.J. Batstone, J.P. Steyer, I. Angelidaki, State indicators for monitoring the anaerobic digestion process. Water Res.44 (2010), 5973-5980. 
332 [6] B.K. Ahring, M. Sandberg, I. Angelidaki, Volatile fatty acids as indicators of process imbalance in anaerobic digestors. Appl. Microbiol. Biotechnol. 43 (1995), 559-565.

[7] O. Lahav, B.E. Morgan, R.E. Loewenthal, Rapid, simple, and accurate method for measurement of VFA and carbonate alkalinity in anaerobic reactors. Environ. Sci. Technol. 36 (2002), 2736-2741.

[8] A.J. Ward, E. Bruni, M.K. Lykkegaard, A. Feilberg, A.P.S. Adamsen, A.P. Jensen, A.K. Poulsen, Real time monitoring of a biogas digester with gas chromatography, near-infrared spectroscopy, and membrane-inlet mass spectrometry. Bioresour.Technol. 102 (2011), 4098-4103.

[9] B. Chatterjee, L. Radhakrishnan, D. Mazumder, New Approach for Determination of Volatile Fatty Acid in Anaerobic Digester Sample. Environ. Eng. Sci. 35 (2018), 1-19.

[10] H.B. Nielsen, H.Uellendahl, B.K.Ahring, Regulation and optimization of the biogas 349 process: Propionate as a key parameter. Biomass Bioenergy 31 (2007), 820-830.

[11] Y. Wang, Y. Zhang, J. Wang, L. Meng, Effects of volatile fatty acid concentrations on methane yield and methanogenic bacteria. Biomass Bioenergy 33 (2009), 848-853.

[12] Y. Xiong, M. Harb, P-Y Hong, Performance and microbial community variations of anaerobic digesters under increasing tetracycline concentrations. Appl. Microbiol. Biot. 101 (2017), 5505-5517.

[13] S. Munir, N. Jamil, Polyhydroxyalkanoates (PHA) production in bacterial co-culture using glucose and volatile fatty acids as carbon source. J. Basic Microb. 58 (2018) 247-254. the measurement of volatile fatty acids. Crit. Rev. Env. Sci. Tec. 46 (2016), 209-234. acids in wastewater by solvent extraction and gas chromatography. Phys. Chem. Earth 67 (2014), 86-92. 
[16] J. Schiffels, M.E.M. Baumann, T. Selmer, Facile analysis of short-chain fatty acids as 4nitrophenyl esters in complex anaerobic fermentation samples by high performance liquid chromatography. J. Chrom.A 1218 (2011), 5848-5851.

[17] H. Turkia, S. Holmström, T. Paasikallio, H. Sirén, M. Penttilä, J-P. Pitkänen, Online capillary electrophoresis for monitoring carboxylic acid production by yeast during bioreactor cultivations. Anal. Chem., 85 (2013), 9705-9712.

[18] M. Dolowy, K. Kulpinska-Kucia, A. Pyka, Validation of a thin-layer chromatography for the determination of hydrocortisone acetate and lidocaine in a pharmaceutical preparation. Sci. World J., (2014) 1-10.

[19] K. Dynska-Kukulska, W. Ciesielski, Methods of extraction and thin-layer chromatography determination of phospholipids in biological samples, Rev. Anal. Chem. 31 (2012), 43-56.

[20] P.K. Zarzycki, M.M. Ślączka, E. Włodarczyk, M.J. Baran, Micro-TLC approach for fast screening of environmental samples derived from surface and sewage waters, Chromatographia, 76 (2013), 1249-1259.

[21] M. Ajmal, A. Mohammad, N. Fatima, A.H. Khan, Determination of microquantities of mercury(II) with preliminary thin-layer chromatographic separation from mercury(I), lead(II), nickel(II), and copper on acid-treated silica gel layers: recovery of mercury(II) from river waters and industrial wastewaters. Microchem. J. 39 (1989), 361-371.

[22] F. Robert-Peillard, E. Palacio-Barco, Y. Dudal, B. Coulomb, J.L. Boudenne, Alternative spectrofluorimetric determination of short-chain volatile fatty acids in aqueous samples, Anal. Chem. 81(2009), 3063-3070.

[23] F. Robert-Peillard, E. Palacio-Barco, B. Coulomb, J.L. Boudenne, Development of a fluorescence-based microplate method for the determination of volatile fatty acids in anaerobically digested and sewage sludges, Talanta 88 (2012), 230-236.

[24] F. Robert-Peillard, J.L. Boudenne, B. Coulomb, Individual volatile fatty acids determination by chromogenic derivatization coupled to multi-syringe chromatography, Talanta 115 (2013), 737-743. 
[25] U.S. Environmental Protection Agency. (2016) Definition and procedure for the determination of the method detection limit, Revision 2. U.S. Environmental Protection Agency.

EPA 821-R-16-006.

[26] E. Kerr, C. West, S.K. Hartwell, Quantitative TLC-image analysis of urinary creatinine using iodine staining and RGB values, J. Chrom. Sci. 54 (2014), 639-646.

[27] A. Pyka, K. Bober, Visualizing agents for short-chain fatty acids in TLC, J. Plan. Chrom. 18 (2005), 145-150.

[28] I.M. Seligman, F.A. Doy, Thin-layer chromatography of N,N-dimethyl-paminobenzolazophenacyl esters of volatile fatty acids and hydroxy acids, Anal. Biochem. 46 (1972), 62-66.

[29] D.Plachá, H. Raclavská, M. Kucerová, J. Kucharová, Volatile fatty acid evolution in biomass mixture composts prepared in open and closed bioreactors, Waste Manage. 33 (2013), 1104-1112.

\section{Figure captions}

Figure 1. Visualization of spots of VFA derivatives with PMA at $3 \%$ in $\mathrm{EtOH}(\mathrm{A})$ and PMA at $3 \%$ in water (B). All VFA at $100 \mathrm{mg} \cdot \mathrm{L}^{-1}$, mobile phase: ethyl acetate/cyclohexane: $60: 40, \mathrm{v} / \mathrm{v}$. Pictures taken out of the box in preliminary experiments.

Figure 2. Influence of mobile phase composition (ethyl acetate/cyclohexane, volume composition) on the separation of VFA derivatives (acetic, propionic, butyric and valeric acid at $\left.100 \mathrm{mg} \cdot \mathrm{L}^{-1}\right) \cdot \mathrm{A}=$ Acetic acid; $\mathrm{P}=$ Propionic acid; $\mathrm{B}=$ Butyric (+ Isobutyric) acid; $\mathrm{V}=$ Valeric (+ Isovaleric) acid.

Figure 3. Visualization of potential interfering compounds after application of the analytical protocol. $\mathrm{C}=$ Citric acid $\left(250 \mathrm{mg} \cdot \mathrm{L}^{-1}\right) ; \mathrm{F}=$ Formic acid $\left(250 \mathrm{mg} \cdot \mathrm{L}^{-1}\right) ; \mathrm{G}=$ Glycine $\left(250 \mathrm{mg} \cdot \mathrm{L}^{-1}\right)$; $\mathrm{VFA}=$ mixture of all VFA at $100 \mathrm{mg} \cdot \mathrm{L}^{-}{ }^{-} ; \mathrm{L}=$ Lactic acid $\left(250 \mathrm{mg} \cdot \mathrm{L}^{-1}\right) ; \mathrm{S}=$ Succinic acid $(250$ $\left.\mathrm{mg} \cdot \mathrm{L}^{-1}\right)$.

Figure 4. TLC picture of a calibration range (10-125 mg. $\left.\mathrm{L}^{-1}\right)$ with associated densitometric histogram (left part); TLC picture of real samples with associated densitometric histogram (right part). Scales for the two histograms are different (optimized by the software on the highest peak). 
442 Table 1. Resolution between VFA peaks on densitometric histograms (with each VFA at $\left.443100 \mathrm{mg} \cdot \mathrm{L}^{-1}\right)$, depending on the mobile phase composition.

\begin{tabular}{ccccc}
\hline $\begin{array}{c}\text { Mobile phase composition } \\
\text { (Ethyl acetate/ Cyclohexane, v/v) }\end{array}$ & $50: 50$ & $60: 40$ & $70: 30$ & $80: 20$ \\
\hline $\mathrm{R}_{\mathrm{S}(\mathrm{V} / \mathrm{B})^{\mathrm{a}}}$ & 0.88 & 1.03 & 0.88 & 0.81 \\
$\mathrm{R}_{\mathrm{S}(\mathrm{B} / \mathrm{P})}{ }^{\mathrm{b}}$ & 1.21 & 1.32 & 1.15 & 1.23 \\
$\mathrm{R}_{\mathrm{S}(\mathrm{P} / \mathrm{A})}{ }^{\mathrm{c}}$ & 1.78 & 2.18 & 2.02 & 2.22 \\
\hline
\end{tabular}

444

Table 2. Analytical features of the proposed method

\begin{tabular}{|c|c|c|c|c|}
\hline Parameter & Acetic acid & Propionic acid & Butyric acid & Valeric acid \\
\hline $\mathrm{Rf}$ & 0.24 & 0.43 & 0.55 & 0.64 \\
\hline $\begin{array}{l}\text { Calibration range } \\
\qquad\left(\mathrm{mg} \cdot \mathrm{L}^{-1}\right)\end{array}$ & $7-125$ & $6-125$ & $5-125$ & $8-125$ \\
\hline Polynomial regression & $y=-1.72 x^{2}+$ & $y=-2.38 x^{2}+$ & $y=-2.26 x^{2}+$ & $y=-1.47 x^{2}+$ \\
\hline equation & $638.5 x+523.7$ & $756.8 x-1812.1$ & $862.8 x-1063.8$ & $721.7 x+167.8$ \\
\hline Correlation coefficient & 0.999 & 0.998 & 0.998 & 0.998 \\
\hline Detection limit $\left(\mathrm{mg} \cdot \mathrm{L}^{-1}\right)$ & 2.1 & 2.0 & 1.5 & 2.5 \\
\hline $\begin{array}{l}\text { Quantification limit } \\
\qquad\left(\mathrm{mg} \cdot \mathrm{L}^{-1}\right)\end{array}$ & 6.7 & 6.3 & 4.7 & 7.9 \\
\hline $\operatorname{RSD}(\%)^{\mathrm{a}}$ & 4.6 & 5.3 & 6.7 & 6.5 \\
\hline
\end{tabular}

a. Resolution between valeric and butyric acid peak.

b. Resolution between butyric and propionic acid peak.

c. Resolution between propionic and acetic acid peak.

Table 3. Operational costs of the analytical protocol described in section 2.3.

\begin{tabular}{llll}
\hline Reagent/material & Quantity & Price & Cost/analysis (€) \\
\hline HOAT & $1.8 \mathrm{mg}$ & $100 € / 25 \mathrm{~g}$ & 0.0072 \\
EDAN & $0.6 \mathrm{mg}$ & $34 € / 25 \mathrm{~g}$ & 0.000816 \\
EDC & $3.5 \mathrm{mg}$ & $50 € / 25 \mathrm{~g}$ & 0,007
\end{tabular}




$\begin{array}{llll}\mathrm{KH}_{2} \mathrm{PO}_{4} & 2.5 \mathrm{mg} & 40 € / 500 \mathrm{~g} & 0.0002 \\ \text { Cyclohexane } & 0.4 \mathrm{~mL}^{\mathrm{a}} & 17 € / \mathrm{L} & 0.00688 \\ \text { Ethyl acetate } & 0.6 \mathrm{~mL}^{\mathrm{a}} & 8.5 € / \mathrm{L} & 0.0051 \\ \text { Phosphomolybdic acid } & 3 \mathrm{~g}^{\mathrm{b}} & 60 € / 100 \mathrm{~g} & 0.009 \\ \text { TLC plates }(6 \times 6 \mathrm{~cm}) & \begin{array}{l}1 / 9 \text { of a full } \\ \text { plate }(20 \times 20 \\ \mathrm{cm})^{\mathrm{a}}\end{array} & 35 € / 25 \text { full plates } & 0,156\end{array}$

Total for 3 samples with duplicate

b. For $100 \mathrm{~mL}$ of PMA solution (usable for $200 \mathrm{TLC}$ plate visualization).

455

456 Table 4. Comparative results between TLC and gas chromatography (GC) analysis on

457 various compost extract samples ( $\mathrm{mg}^{\mathrm{L}} \mathrm{L}^{-1}$, mean \pm standard deviation, $\mathrm{n}=2$ replicates).

\begin{tabular}{|c|c|c|c|c|c|c|c|c|}
\hline & \multicolumn{2}{|l|}{$\mathrm{C} 2$} & \multicolumn{2}{|l|}{ C3 } & \multicolumn{2}{|l|}{ C4 } & \multicolumn{2}{|l|}{ C5 } \\
\hline & GC & TLC & GC & TLC & GC & TLC & GC & TLC \\
\hline AN1 & $68.7 \pm 2.5$ & $63.8 \pm 3.2$ & $9.5 \pm 1.9$ & $7.1 \pm 2.1$ & $16.2 \pm 1.0$ & $14.8 \pm 4.1$ & $15.3 \pm 0.2$ & $12.0 \pm 1.2$ \\
\hline AN2 & $80.2 \pm 1.7$ & $88.7 \pm 10.1$ & $11.0 \pm 0.6$ & $8.3 \pm 1.3$ & $19.0 \pm 1.4$ & $17.2 \pm 0.9$ & $18.6 \pm 0.1$ & $14.4 \pm 0.8$ \\
\hline AN3 & $131.1 \pm 5.4$ & $121.2 \pm 5.6$ & $14.7 \pm 2.2$ & $10.0 \pm 2.4$ & $23.3 \pm 0.7$ & $18.3 \pm 3.8$ & $14.9 \pm 0.6$ & $12.9 \pm 1.4$ \\
\hline AN4 & $41.6 \pm 4.7$ & $36.4 \pm 2.3$ & $12.2 \pm 0.5$ & $11.4 \pm 1.3$ & $13.2 \pm 1.2$ & $9.5 \pm 2.0$ & $3.7 \pm 0.2$ & $<L Q$ \\
\hline AN5 & $36.9 \pm 0.3$ & $29.8 \pm 6.8$ & $5.4 \pm 0.1$ & $<L Q$ & $7.9 \pm 0.3$ & $5.3 \pm 1.0$ & $5.2 \pm 0.5$ & $<L Q$ \\
\hline
\end{tabular}




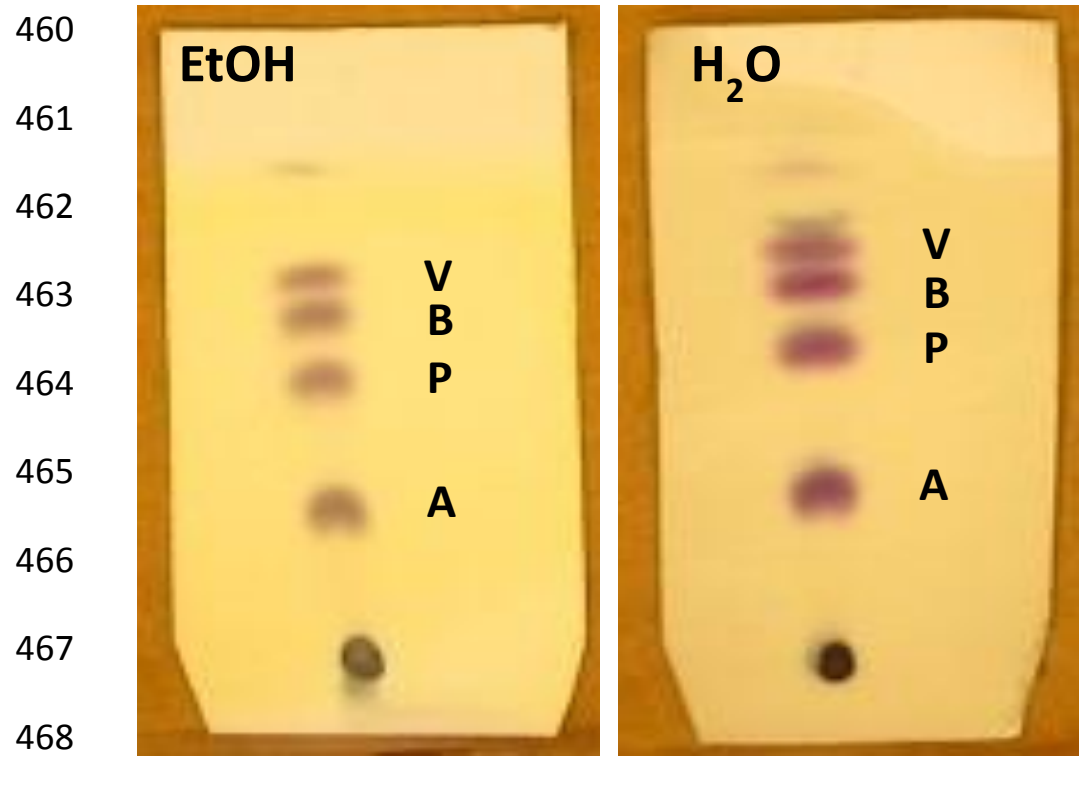

$469 \quad$ Figure 1

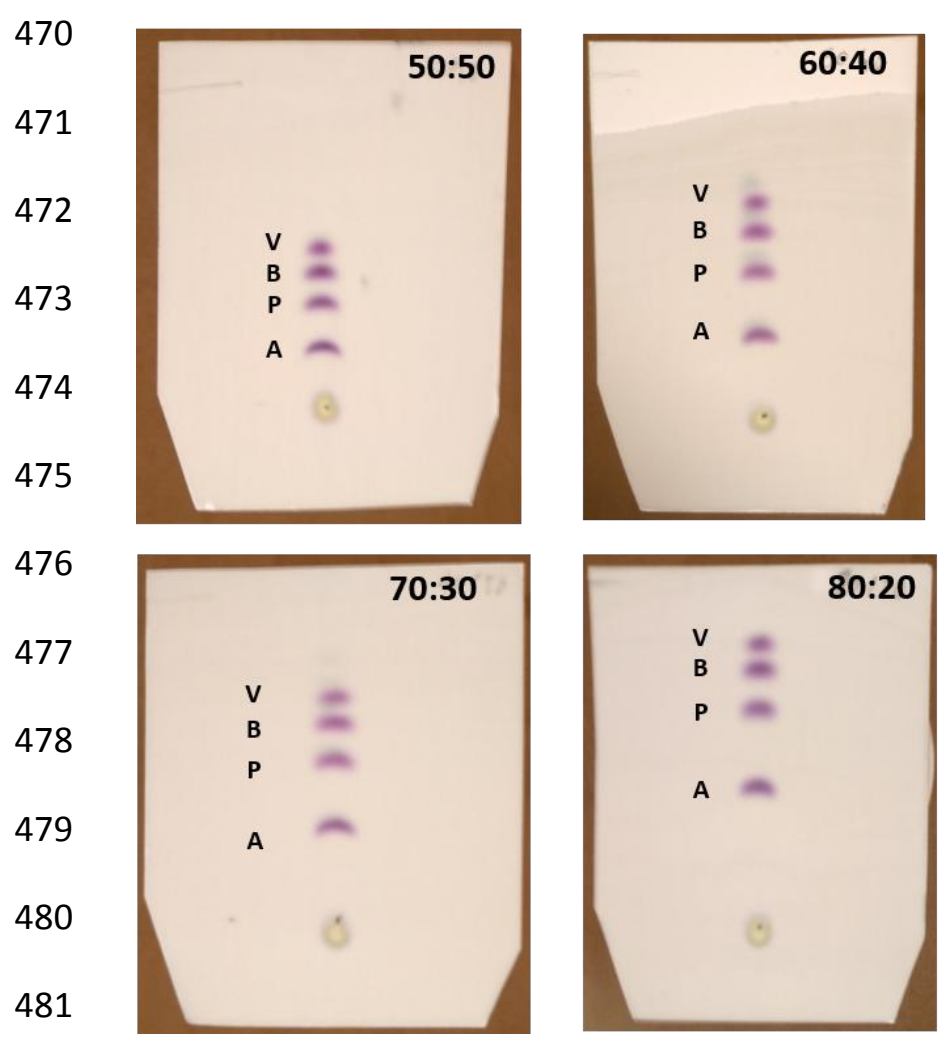

$482 \quad$ Figure 2

483

484

485

486 


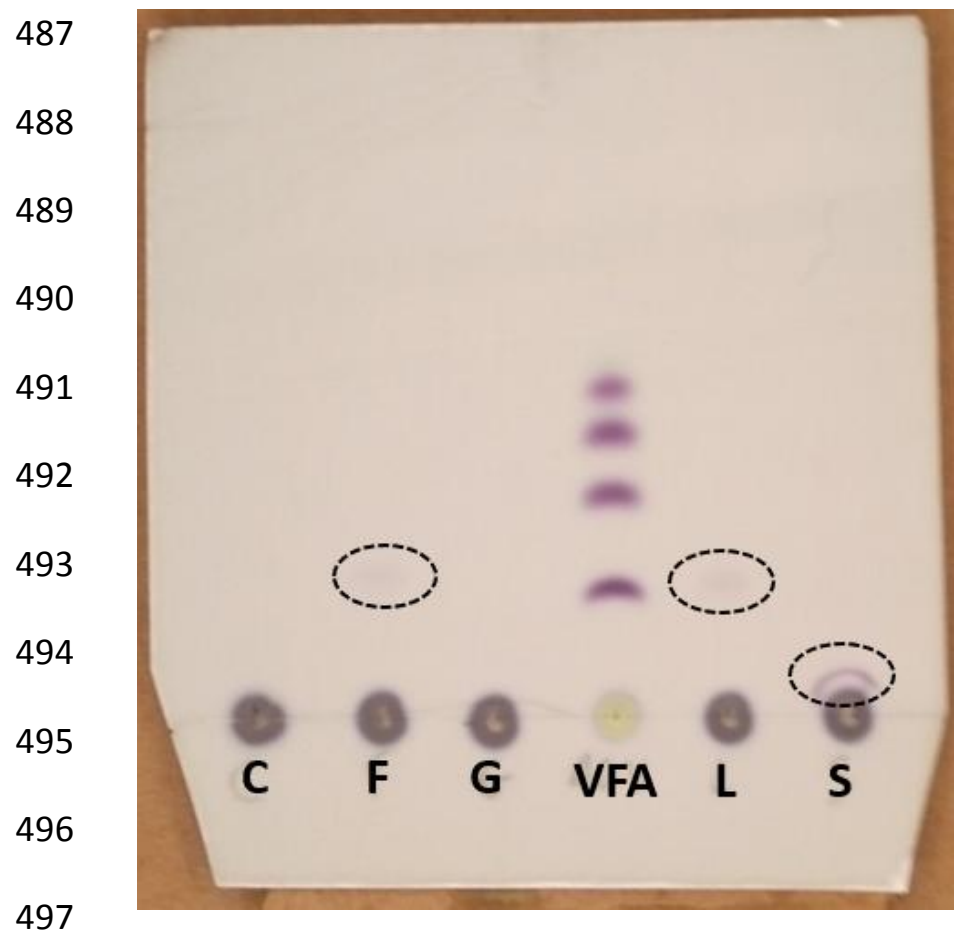

$498 \quad$ Figure 3

499

500

501

502

503

$\begin{array}{llllll}10 & 20 & 35 & 55 & 85 & 125\end{array}$

504

505

506

507

508

509

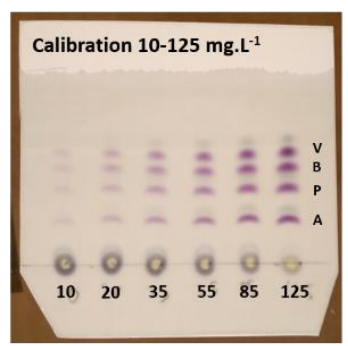

Real samples

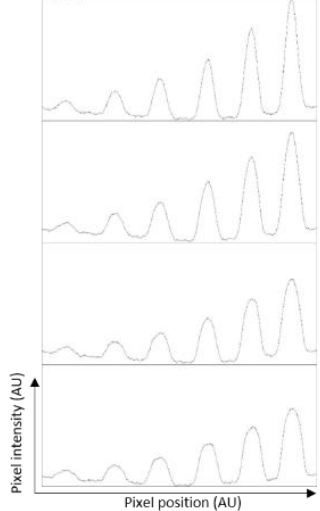

Valeric acid (V)

Butyric acid (B)

Propionic acid (P)

Acetic acid (A)

510

$511 \quad$ Figure 4

512

513 
